\title{
Numerical Modeling of Stalagmite Vibrations
}

\author{
Katalin Gribovszki, ${ }^{1,2}$ (D) Sofi Esterhazy, ${ }^{1}$ and Götz BoKelmanN ${ }^{1}$
}

\begin{abstract}
Recently, it has been argued that natural, intact stalagmites in caves give important constraints on seismic hazard since they have survived all earthquakes over their (rather long) life span. This suggests that the pattern of oscillation should be fully understood, including the splitting of eigenfrequencies that has occurred in recent cave observations. In the present study, we simulate the oscillation of a given stalagmite by setting up four simplified models of the stalagmite. The dimensions of the intact stalagmite were measured in situ, and the geo-mechanical and elastic parameters of broken stalagmite samples, determined in geo-mechanical laboratory, have been taken into account. The eigenfrequencies of the stalagmite are then calculated numerically, by the finite element method, and compared with the measured in situ values. The latter have shown splitting of eigenfrequencies, which we were able to reproduce by the numerical model calculations taking into account the asymmetric shape of the stalagmite.
\end{abstract}

Key words: Earthquake, palaeoearthquake, stalagmite, finite elements, seismic hazard, eigenfrequency, asymmetry.

\section{Introduction}

The main motivation for this numerical modeling study comes from the wish to better understand seismic hazard, a problem with important social and economic implications. The occurrence of strong earthquakes is well-known at many plate boundaries, but especially in intraplate regions, the seismicity rate can be low. Recurrence intervals of large earthquakes can be as long as 10,000 years (Scholz 1990) and may thus be overlooked (Calais et al. 2016). In such areas, the missing long-term information about past earthquakes makes it very difficult to appropriately estimate the seismic hazard. The long-term

1 Department of Meteorology and Geophysics, University of Vienna, Vienna, Austria. E-mail: katalin.gribovszki@univie.ac.at

2 Geodetic and Geophysical Institute, Research Centre for Astronomy and Earth Sciences, Hungarian Academy of Sciences, Sopron, Hungary. information of earthquakes in Central Europe is missing since the instrumental seismic records go back only for about a century and even the historical reports generally provide too short and incomplete coverage of the past (Zsíros 2000; Tóth et al. 19962014). In principle, such long-term information may be gained from the traces of strong palaeoearthquakes that pre-date the available catalog information, or from the absence of such traces. The latter may in principle be established by the continued existence of speleothems that are still intact in the pertaining region, indicating a lack of earthquakes strong enough to destroy them (Boch 2008; Szeidovitz et al. 2008a, b; Gribovszki et al. 2008, 2013a, b, 2017). For stalagmites that have survived, we are able to estimate the horizontal ground acceleration that would have made them failed at different stages of their growth. It can then be concluded that the ground acceleration has not exceeded the estimated value ever since the growth stage for which it was computed. Such information can be crucial for properly estimating the seismic hazard.

In order to evaluate the vulnerability of speleothems to earthquakes, it is necessary to know the range of their natural frequencies, since the speleothem can undergo dynamic amplification during excitation. Therefore in order to determine the behaviour of speleothems under seismic action, it is necessary to have information about the natural frequency band of such speleothems (Lacave et al. 2000). Only very elongated, thin and long speleothems are subject to the dynamic amplification phenomena, because their natural frequencies are within the seismic frequency range (around 0.1-30 Hz). These dripstones could undergo such amplification that might lead to their rupture during a real earthquake (Lacave et al. 2004) and we are investigating that kind of dripstones. This means that 
they have much higher probability to fail with a lower ground acceleration value than in static case, when speleothems move as rigid objects together with their base.

In Bao et al. (2014) resonance frequency was calculated by numerical discontinuous deformation analysis (DDA) method and measured as well. DDA method to perform site response analysis of free standing columns can be found in that study. The ability of DDA to simulate wave propagation through structures is tested by comparing the resonance frequency obtained for a multidrum historical monument column when modelling it with DDA and testing it in the field using geophysical site response survey.

Our study was mainly motivated by the reason that the eigenfrequencies of the stalagmite measured in situ have not been fully reproducible by simple analytical calculations. Therefore we set up a numerical modeling approach to predict the eigenfrequencies of the stalagmite we investigated, assuming a variety of geometrical shapes. Do these match the values measured in situ if we take into account realistic geometrical features of the stalagmite? Is the assumed (non-realistic) symmetric shape the reason why the calculated natural frequencies (Gribovszki et al. 2013a) differ from the measured ones? A previously unexplained feature was the splitting of the harmonic oscillations. We address whether numerical computation can reproduce that phenomenon or whether this is an artifact of the in situ measurement method.

First, we present the stalagmite that gave rise to this study. Then we explain how we determined the eigenfrequencies by using the recorded in situ vibration (field observation). Afterwards we briefly review the theoretical basis for the numerical modeling, and show in detail the different computations that were done, their results and the comparison with the field observations made in the cave. Finally, we test the numerical model computation with the analytical solution and discuss the possible reasons of the splitting of eigenfrequencies.

\section{The Investigated Stalagmite in the Domica Cave} and the Measured Parameters of Broken Samples

The stalagmite that we investigated in situ (Fig. 1) is standing in the Ördög-lik Hall ( $\breve{\mathrm{C}}$ ertova diera) of the Domica cave, which is the Slovakian part of the Baradla-Domica cave system located in Northeastern Hungary. The height of this candlestick-shaped (tall, slim and more or less cylindrically-shaped) stalagmite is about $4.6 \mathrm{~m}$; the average diameter of it is about 5-6 cm (Table 1). Measuring more precisely the dimensions of the stalagmite in the cave was difficult, since it is rather difficult to approach.

The elastic parameters and the mechanical properties, which were used for the model calculations (analytic and numerical as well), were determined in a mechanical laboratory (Gribovszki et al. 2013a; Konecny et al. 2015), and by in situ vibration measurements in the cave. Mechanical laboratory measurements were performed on samples originating from stalagmites, which were found lying broken on the ground in the Ördög-lik Hall of Domica cave. The dynamic Young's modulus $(E)$ was determined from ultrasonic Vp and Vs values (Nováková et al. 2011). The latter were measured by the direct pulse transmission technique using a portable digital

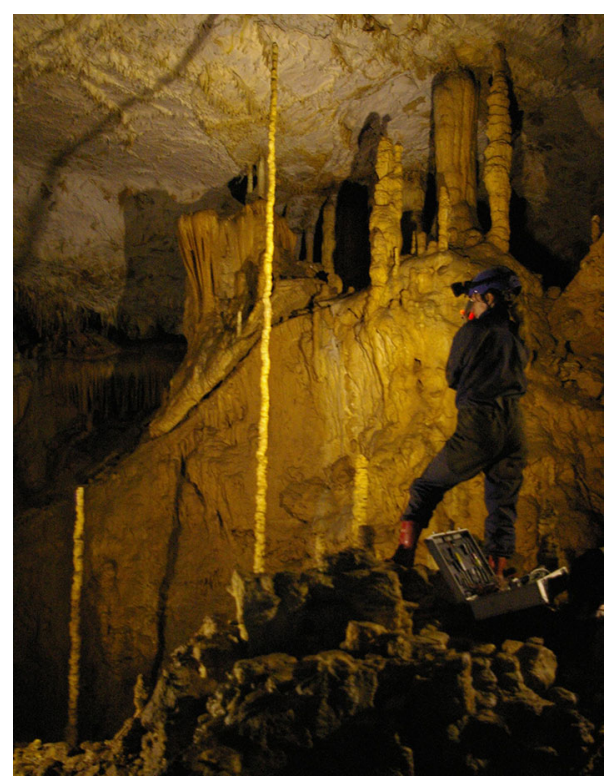

Figure 1

The intact, candlestick-shaped stalagmite that we investigated in the Domica cave, Ördöglik Hall (Slovakia) 
Table 1

Dimensions of the stalagmite we investigated and elastic and mechanical properties of broken stalagmite samples collected from the same cave

Length (measured in situ)

Thickness (measured in situ)

Dynamic Young's modulus (measured in the lab)

Poisson's ratio (measured in the lab)

Density (measured in the lab)

Damping factor (calculated from the recorded vibration)

$$
\begin{aligned}
& H=4.6 \pm 0.3 \mathrm{~m} \\
& D=2 r=5-6 \mathrm{~cm} \\
& E=33.6 \pm 0.4 \mathrm{GPa} \\
& v=0.1 \\
& \rho=2347.6 \pm 115.8 \mathrm{~kg} / \mathrm{m}^{3} \\
& \eta_{s}=0.00048
\end{aligned}
$$

ultrasonic instrument (Pundit Lab + , Proceq Company), and the measurements were carried out in the mechanical laboratory of the Institute of Geonics of the Czech Academy of Sciences (Konecny et al. 2015). The dimensions and the relevant elastic and geo-mechanical parameters of the stalagmite are listed in Table 1. MC-ICP-MS age determinations have shown that this stalagmite is not older than eight thousand years (Gribovszki et al. 2013a).

In the model computations, isotropic elastic properties of the stalagmite have been assumed, therefore only one value determining each property was enough.

\section{The In Situ Non-Destructive Vibration Measurements in the Cave}

The vibration of the stalagmite we investigated was recorded twice in situ in 2012 and in 2013, and by two different sensors and data loggers. The first measurements were carried out in 2012 and have been documented in Gribovszki et al. (2013a). The second in situ measurements were performed in 2013. At that time, a low-frequency geophone (type LF-24) was fastened onto the stalagmite in order to record its vibration. The geophone eigenfrequency is $1 \mathrm{~Hz}$; it has a built-in nonlinear correction pre-amplifier (its weight is $0.3 \mathrm{~kg}$ ). A Reftek 130S-01 data logger was also used ( 24 bit, AD converter). A special coupling sensor holder was built to ensure sufficient mechanical connection between the stalagmites and the geophone and to precisely adjust the horizontal position of the geophone.

The stalagmite was excited by hitting it gently with a finger. The vibration of the excited stalagmite was recorded (Fig. 2), and it was later analyzed in the office and the natural frequencies of the stalagmite have been determined. As shown in Fig. 2 and Table 2 the power spectral density of vibration indicates that the eigenfrequency of the stalagmite is around $2.1 \mathrm{~Hz}$, and the first higher harmonics are about 10.2 and $10.6 \mathrm{~Hz}$. Such a low natural frequency could very well occur during a local earthquake (Lacave et al. 2000, 2004), and put the stalagmite in resonance.

In the following we will call the set of eigenfrequencies plus higher oscillations the "eigenfrequencies". For the higher frequencies, around 10 and $26 \mathrm{~Hz}$, the harmonic oscillations split into two individual spectral lines (see Fig. 2 and Table 2). We will discuss this in the later part of this paper, and model the splitting of eigenfrequency by numerical computations. Such a splitting is not apparent for the eigenfrequency itself, at $2.1 \mathrm{~Hz}$, but such a splitting may perhaps be hidden by the limited frequency resolution of $0.16 \mathrm{~Hz}$, which is due to the limited length of the time window.

\section{Deformation Model for Stalagmites}

\subsection{Linear Elasticity Theory}

The motion of a stalagmite under seismic forces can be described by the linear elastic wave equation:

$$
\rho \ddot{u}+\eta_{s} \dot{u}=-\nabla \cdot \sigma+F,
$$

where $\rho$ represents the medium density, $\ddot{u}$ is the acceleration of the unknown displacement $u$, and $F$ denotes the seismic excitation force. The damping of the material is included by the coefficient $\eta_{s}$. $\sigma$ denotes the stress tensor, which is linearly related to the strain by the constitutive equation: 
(a)

Domica - 2013-11-07T12:17:42.000000Z
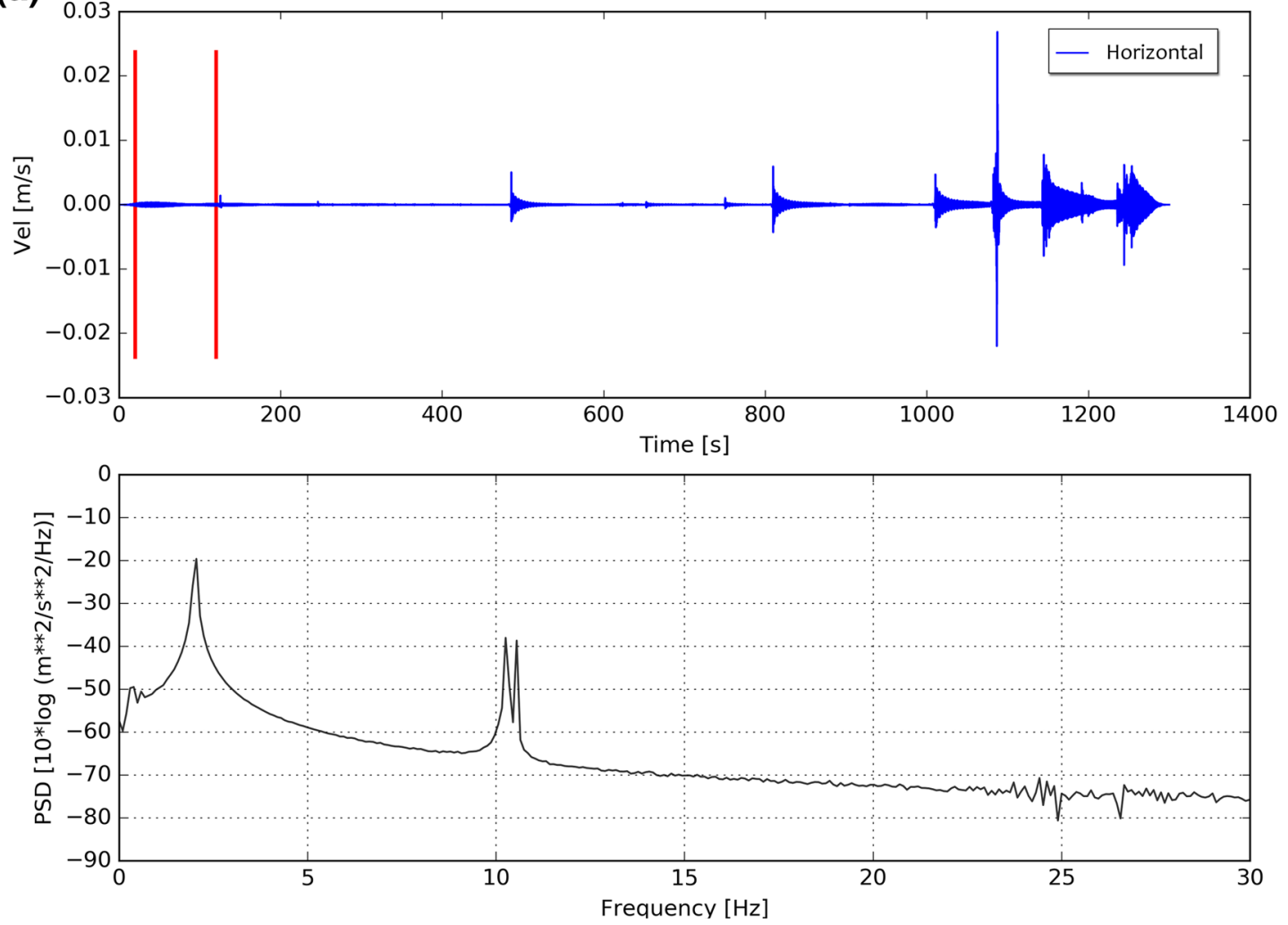

(b)

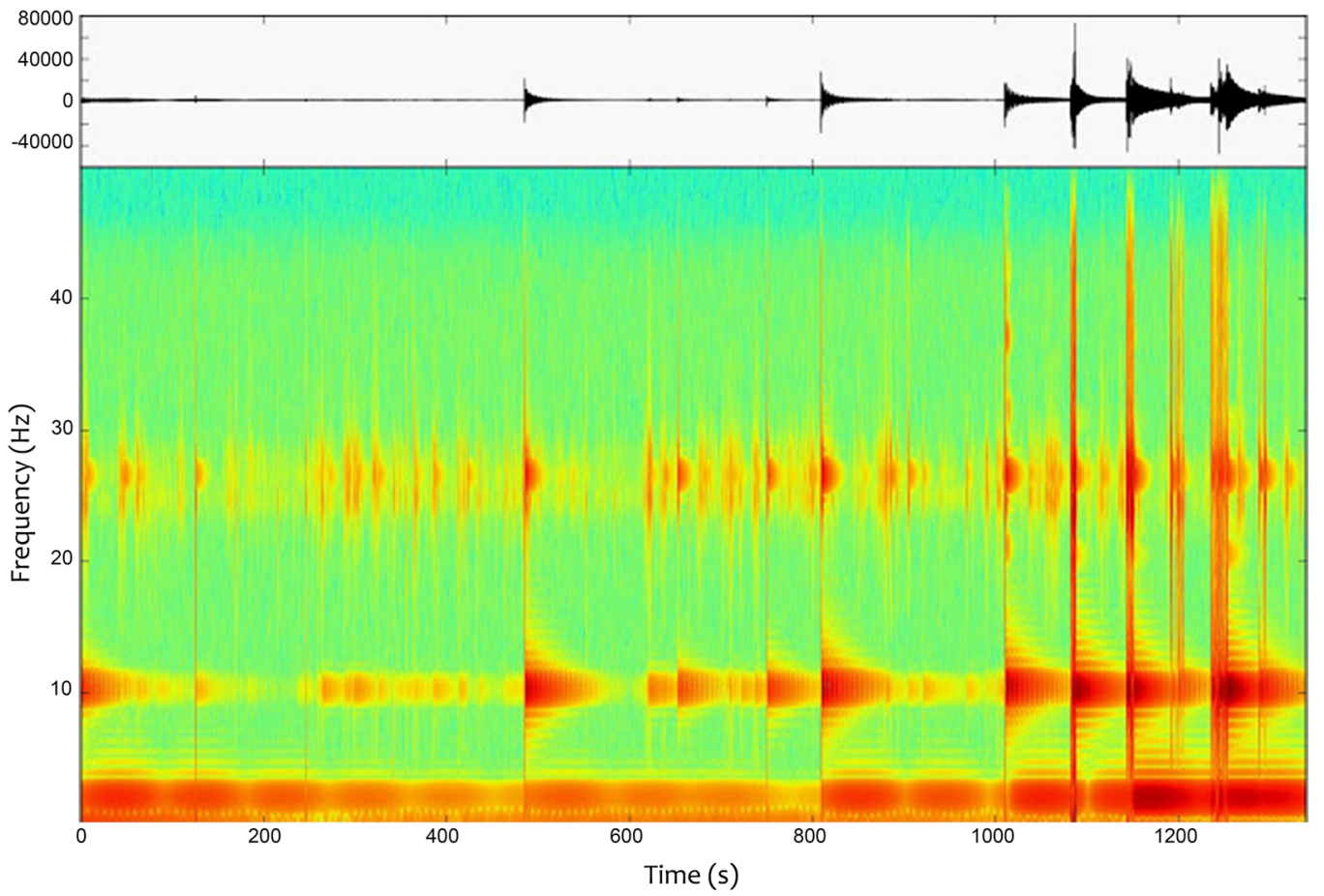


Figure 2

Excitation spectrum of the stalagmite: a the recorded vibration and spectrum of part of it in $\mathrm{Hz}, \mathbf{b}$ vibration and spectrogram showing the repeated excitation by a gentle hit recorded in 2013

$$
\sigma=C \varepsilon
$$

while the strain tensor is defined by:

$$
\varepsilon=\frac{1}{2}\left(\nabla u+\nabla u^{T}\right)
$$

and the fourth-order stiffness tensor $\mathrm{C}$ for isotropic media with Lamé constants $\lambda$ and $\mu$ is given elementwise by:

$$
C_{i j k l}=\lambda \delta_{i j} \delta_{k l}+\mu\left(\delta_{i k} \delta_{j l}+\delta_{i l} \delta_{j k}\right),
$$

where $\delta_{i j}$ denotes the Kronecker symbol.

Another important case of dynamic problems is the eigenoscillation problem (EOP) for an elastic body with surface stresses (Altenbach et al. 2013; Day and Romero 2004). In this case we seek timeharmonic solutions of the homogeneous dynamic Eq. (1) with $F=0, \quad$ in the form $u=u(x, t)=w(x) e^{i \omega t}$. Substituting this into (1) and cancelling the factor $e^{i \omega t}$, we get:

$$
\nabla \cdot \sigma=-\rho \omega^{2} w,
$$

where $\omega$ is the frequency of motion.

Alternatively, it is common to use the EulerBernoulli beam theory as a simplification of the linear theory of elasticity for transverse vibration which provides a means for calculating the load-carrying and deflection characteristics of beams. It covers the case for small deflections of a beam that is subject to lateral loads. However, the Euler-Bernoulli beam theory does not account for the effects of transverse shear strain. As a result it underpredicts deflections and overpredicts natural frequencies. A more accurate approach is the Timoshenko theory, which also includes shear and rotation inertia. Although this theory gives remarkably accurate results compared to a two-dimensional model, not all types of disturbances can be modelled appropriately, see Labuschagne et al. (2009); Pilkey (2002). Overall, stalagmites are not unlike other common elements in mechanical engineering structures, like beams, trusses, etc., and they can be treated similarly.

\subsection{Boundary Conditions and Loadings}

There exist several types of boundary conditions for elastic media. For our purpose the most important one is the free-surface boundary, which we apply to the entire surface of our stalagmite model except for the ground interface. On the latter we will either impose clamped or fixed boundary conditions or prescribe a given load source.

The free surface condition requires that surface tractions are zero, both for tangential and normal stress components. With the normal vector $\mathrm{n}$ acting on the surface this condition is given by:

$$
n \cdot \sigma=0
$$

While the fixed boundary condition can be expressed by $u=0$, there are also numerous types of loads that can be applied. Depending on the problem configuration and the numerical modeling, seismic waves and seismic motion can be modelled for example by a point source (which may, however, be numerically unstable in some cases) or an incident plane wave. The gravity body force is also taken into account for every part of the model.

\subsection{Numerical Computation Method}

A common numerical technique for solving problems in mechanical engineering is the Finite Element Method (FEM). It gives great flexibility for modeling

Table 2

Dimensions and natural frequencies measured by non-destructive in situ examinations of the stalagmite that was studied (observed data in Table 3, second column)

\begin{tabular}{llllll}
\hline Height $(\mathrm{m})$ & Diameter $(\mathrm{cm})$ & H/D & Measured $f_{0}(\mathrm{~Hz})$ & Measured $f_{1}(\mathrm{~Hz})$ & Measured $f_{2}(\mathrm{~Hz})$ \\
\hline $4.60 \pm 0.3$ & Average: $5-6$ & $98-70$ & 2.1 & $10.2 ; 10.6$ & $25 ; 26.5$ \\
\hline
\end{tabular}




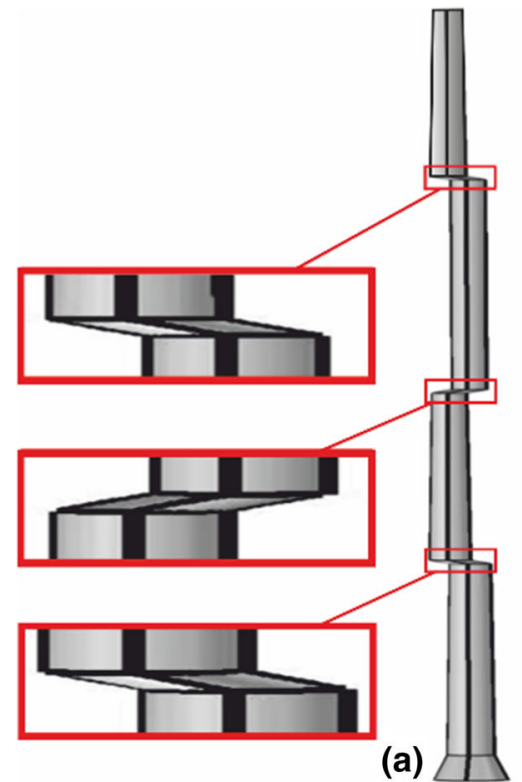

(b)

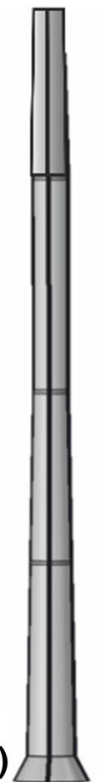

(c)

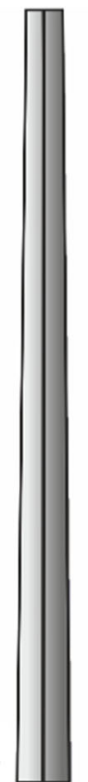

(d)

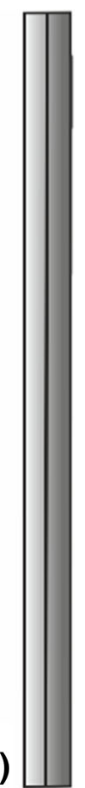

Figure 3

Different geometries of the stalagmite a asymmetric model Model A, b the symmetric model Model B, $\mathbf{c}$ the cone Model C, and $\mathbf{d}$ the cylinder Model D (depicted in four-fold horizontal exaggeration)

complex geometries and can easily handle any type of general boundary conditions and variable material properties. FEM has a solid theoretical foundation, which gives added reliability and makes it possible to mathematically analyze and estimate the error in the approximate solution. A detailed explanation of this numerical scheme is given in Appendix 1.

The Finite Element numerical calculations that we will present in the following have been done by COMSOL Multiphysics software, Structural Mechanics Module, Solid Mechanics interface.

\section{Numerical Examples and Applications}

\subsection{Models for the Stalagmite}

For modeling the eigenfrequencies of the stalagmite, we have constructed four approximate models to test the effect of different features of the stalagmite model. This approach helps us to understand where the observed phenomenon may be coming from. An alternative approach might be to produce a full model of the stalagmite surface, and to enter this into the modeling. However, a 3D laser scanner was not available, since the path to approach the stalagmite was quite difficult and narrow, and it would not have helped to isolate the cause of the observed phenomena. We chose to use approximate stalagmite shapes. This approximate shape was constructed on the basis of pictures of the stalagmite taken from different angles in the cave. The first model (Model A) contains the largest complexity, and this model is the most similar to the real geometry of the stalagmite, consisting of a series of cylinders and cones; the second one (Model B) corresponds to the first one, but the asymmetric parts are centered; the third model (Model C) consists of a single elongated cone, and the fourth model (Model D) is a cylinder with average diameter of the real stalagmite. The four models are illustrated in Fig. 3, with a concise presentation of the corresponding parameters in Appendix 2.

\subsection{Natural Eigenfrequencies}

Based on the formulation of the EOP in Eq. (5), we computed the natural frequencies by using the COMSOL Multiphysics Eigenfrequency Study, (the mesh type was set to "extra fine") and the resulting 
Table 3

Comparison of observed with predicted eigenfrequencies from the four models in Fig. 3 (in $\mathrm{Hz}$ )

\begin{tabular}{llllll}
\hline & Observed & $\begin{array}{l}\text { Model A } \\
\text { Asymmetric }\end{array}$ & $\begin{array}{l}\text { Model B } \\
\text { Symmetric }\end{array}$ & $\begin{array}{l}\text { Model C } \\
\text { Cone }\end{array}$ & $\begin{array}{l}\text { Model D } \\
\text { Cylinder }\end{array}$ \\
\hline$f_{0}$ & 2.1 & 2.096 & 2.097 & 2.161 & 1.494 \\
$f_{1 x}$ & 10.2 & 12.124 & i.q. & i.q. & i.q. \\
$f_{1 y}$ & 10.6 & 10.207 & 10.082 & 10.703 & 9.359 \\
$f_{2 x}$ & 25 & 25.983 & i.q. & i.q. & i.q. \\
$f_{2 y}$ & 26.5 & 26.381 & 26.172 & 27.931 & 26.184 \\
\hline
\end{tabular}

values were compared to the ones observed in the Domica cave Ördöglik Hall, as shown in Table 3 and illustrated in Fig. 4. The element size of the mesh applied ( $\sim 7 \mathrm{~mm}$ ) comparing it to the wave length was suitable, as it was written in Lysmer and Kuhlemeyer (1969). The width of the pink bar in Fig. 4 shows the uncertainty of the observed eigenfrequencies $( \pm 0.16 \mathrm{~Hz})$, which results from the finite temporal observation window. The corresponding spectrum, in which the frequencies were determined (observed values), is shown in Fig. 2.

The model with an asymmetric shape (Model A) has produced split frequencies for all three frequency groups, including the eigenfrequency. For that lowest eigenfrequency, the observed value is indeed situated between the two predicted ones. The higher predicted eigenfrequencies are either equal to the lower value of the observed split frequencies or they are between the two observed values and almost equal to the higher one (one of the predicted split frequencies is within the observational uncertainty). Therefore, we can state that the values determined by finite element computations assuming an asymmetric shape of the stalagmite are very close, and indeed almost equal to the observed ones. No assumed symmetrical shape of the stalagmite produced any splitting of the dominant frequencies.

\section{Discussion}

We can verify the Finite Element solution by comparing the eigenfrequencies that resulted from the numerical Model D (the cylinder), with eigenfrequencies that we computed from an analytical solution following Kong et al. (2008):

$$
f_{i}=\alpha_{i} \sqrt{\frac{E D^{2}}{16 \rho H^{4}}},
$$

where $\quad \alpha_{0}=0.559 ; \quad \alpha_{1}=3.507 ; \quad \alpha_{2}=9.820$; $\alpha_{3}=19.244 ; \alpha_{4}=31.808 ; \mathrm{D}$ is the average diameter, $\mathrm{H}$ is the height of stalagmite, $\rho$ is the mass density of the stalagmite, $\mathrm{E}$ is the dynamic Young's modulus (see also Bednárik 2009; Gribovszki et al. 2017). The latter values are given in Table 4, and they show indeed a rather good correspondence with the numerical values in the far right column of Table 3. That suggests that the eigenfrequencies for the other models are trustworthy.

The only model, which produces frequency splitting, is the asymmetric Model A. This strongly suggests that the splitting is due to the asymmetry in the stalagmite. The splitting occurs in Model A for all three groups of frequencies, while the observations have shown the splitting only for the two higher frequency groups. The missing splitting for the lowest frequency can be easily explained by the relatively short time window, which results in a frequency resolution that is too low to observe the splitting. Clearly, the frequency splitting is not an artefact of the in situ measuring method.

The nature of the frequency splitting is thus similar, to the splitting of Earth's normal modes (e.g., Aki and Richards 1981), which is created by Earth's (internal and external) aspherical structure, as well as its rotation and anisotropy. Such splitting has recently become of interest also for engineering purposes (e.g., Vallabhaneni et al. 2013), since it may help characterize deviations from structural symmetry, 


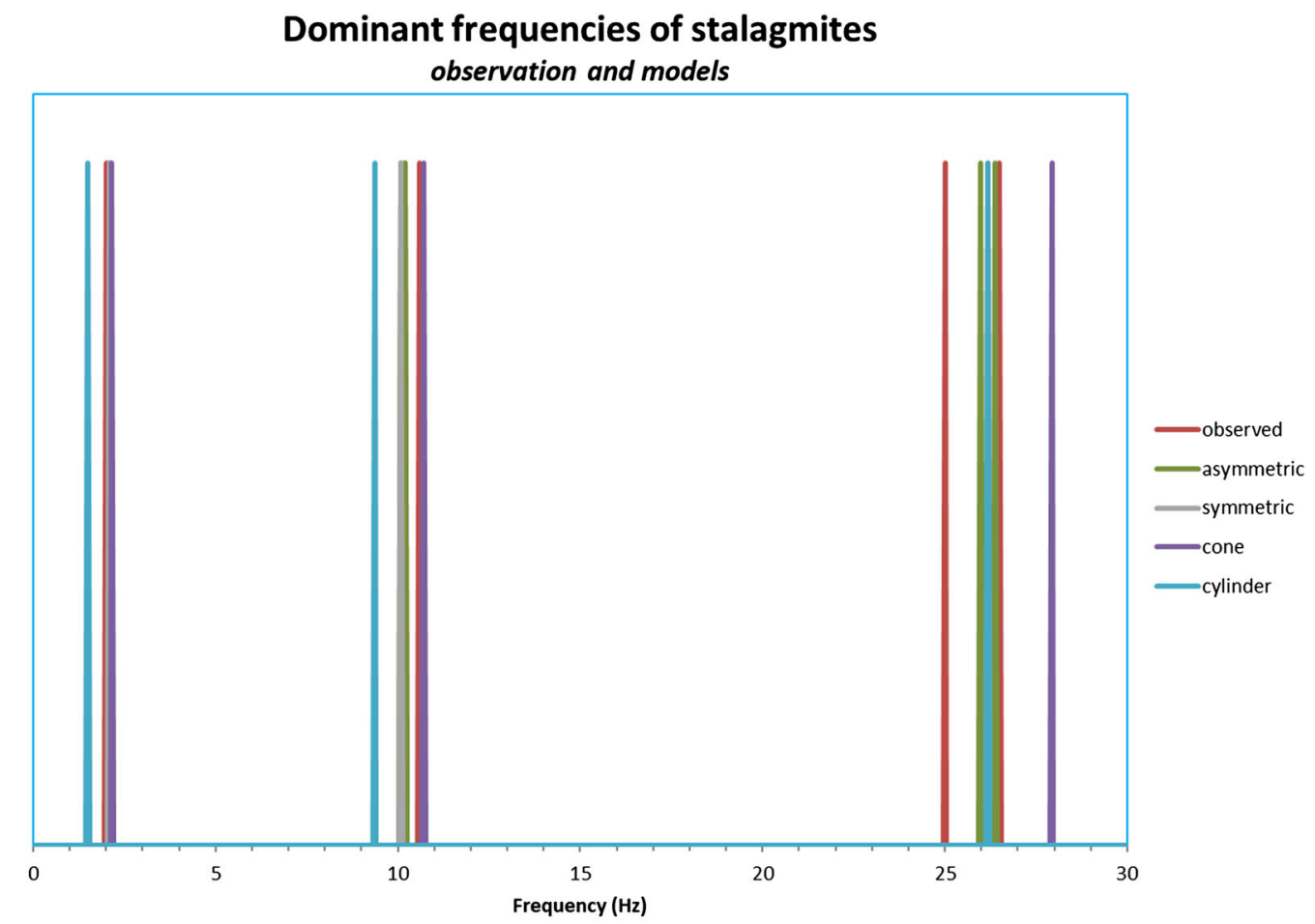

Dominant frequencies of stalagmite oscillations (observation and models) in the entire frequency range

\section{Dominant frequencies of stalagmites}

observation and models

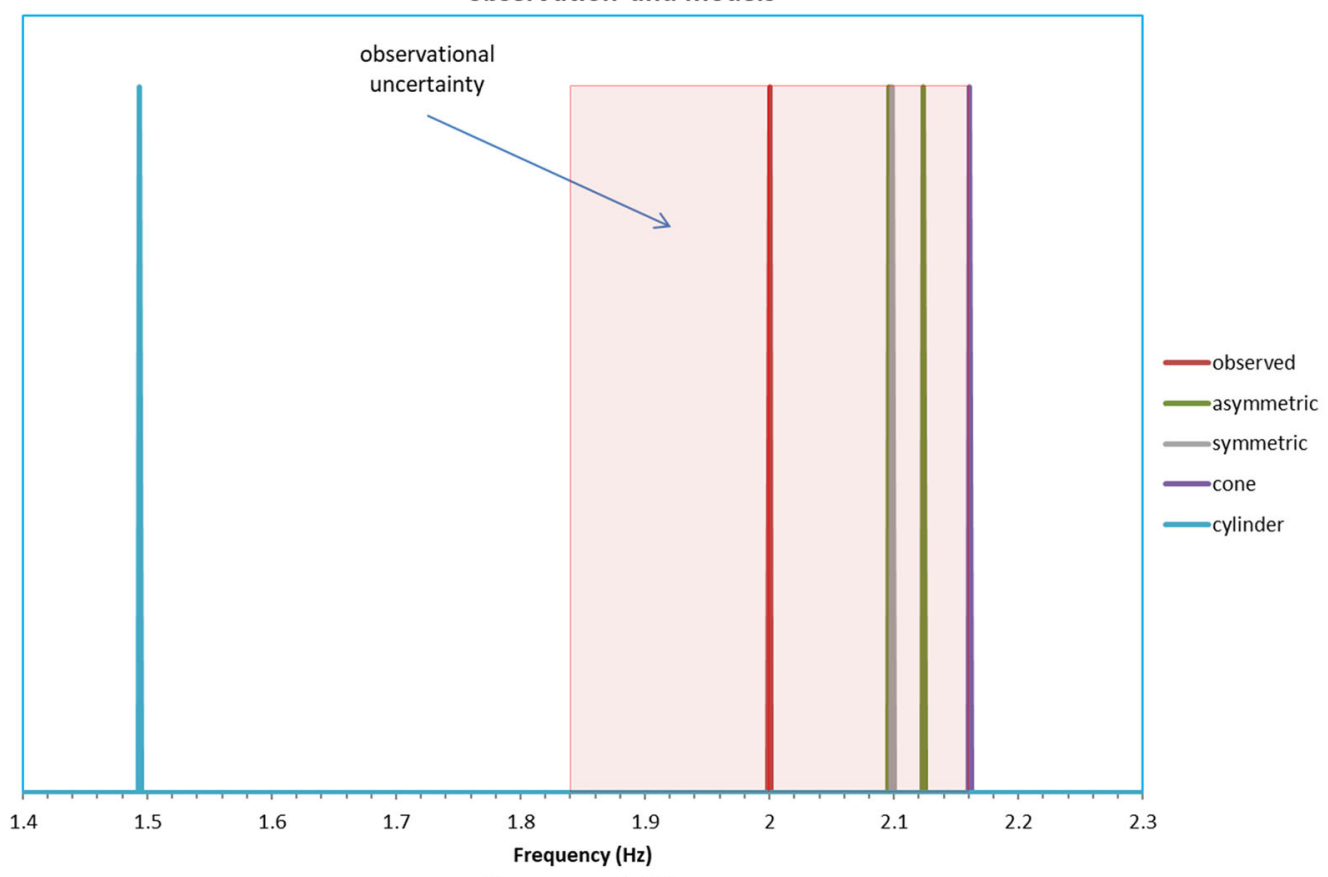

Zoom around $2 \mathrm{~Hz}$

Figure 4

Comparison of observed and predicted frequencies from the four models in Fig. 3. The pink areas represent the accuracy of observed dominant frequencies 


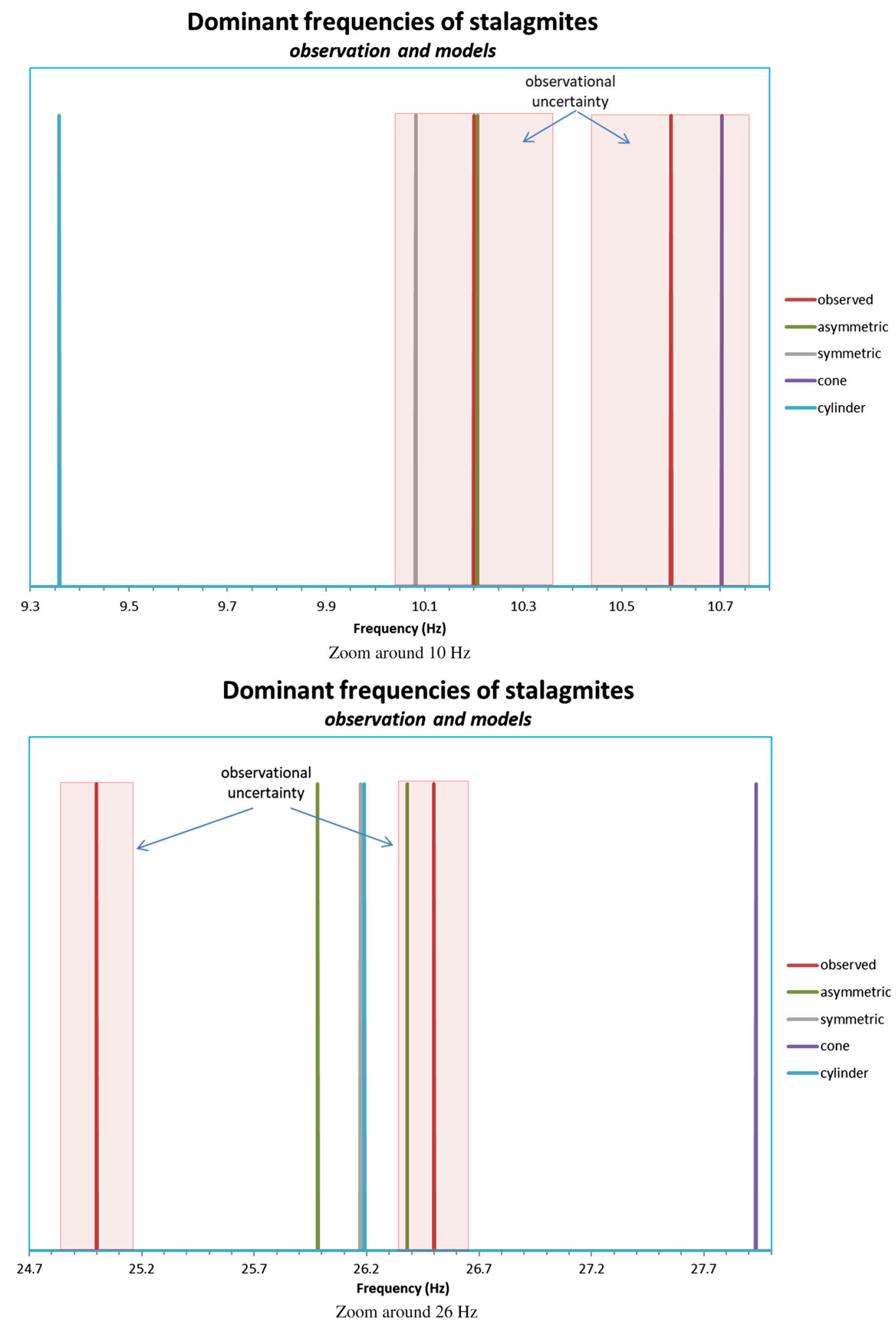

Figure 4

continued 
Table 4

Calculated eigenfrequencies from the analytic solution, Eq. (7)

$f_{0}(\mathrm{~Hz}) \quad f_{1}(\mathrm{~Hz})$ theoretical $\quad f_{2}(\mathrm{~Hz})$ theoretical

theoretical

1.497

$9.390=1.497 \times 6.27426 .293=9.390 \times 2.800$

e.g., due to internal defects. The splitting is generally stronger, the stronger the asymmetry is. The orientation of defects (cavities) matters, while the total volume of the cavities seems to matter less. A more direct comparison of the stalagmite oscillation is perhaps with that of rings and bells (e.g., Allaei et al. 1986). Analytical modeling has shown that a point mass non-uniformity shifts the higher natural frequencies more than the lower ones in an absolute sense. The percentage change of the frequencies increases up to a certain mode and then decreases for the rest of the modes.

The observed splitting is well-explained by the asymmetric model, except that it is 3 to 4 times as strong as in the numerical prediction. Such a difference may result from asymmetries in the outer shape of the stalagmite, asymmetries in the internal structure, and from the necessary fixing of the measuring sensor onto the stalagmite.

The outer shape of the stalagmites does indeed appear much more complex than we could realize in the numerical model: there were many more irregularities of the shape, and they occur in both horizontal directions. Our model considers only deviations in a single direction. The internal structure of the stalagmite is also more irregular than we have assumed, both in the arrangement of the different calcareous aggregates, and in the pore spaces. A cut portion of another stalagmite has shown pore spaces within the stalagmite, which have a very complex shape. This likely leads to anisotropic elastic properties of the stalagmite. In principle, tomographic techniques may reveal the internal structure of stalagmites (Gribovszki et al. 2017, Fig. 8 and Konecny et al. 2015, Figs. 3, 4, images of X-ray micro-tomograph and computed tomograph). Furthermore, we have experimented with different portable ultrasound techniques and an acoustic tomographic measuring device originally intended for studying the structure of trees (ArborSonic3D), and this gave reasonable results
(Hegymegi et al. 2016) in laboratory, but the stalagmite of interest is too difficult to access for this kind of measurements. External and internal heterogeneity can very well explain the discrepancy in the size of the frequency splitting.

On the other hand, the effect of the oscillation sensor is likely to be of less importance. The $0.3 \mathrm{~kg}$ weight horizontal geophone, which was fastened to the stalagmite to record its vibration, represents only a few percent of the mass of the asymmetric part of the real stalagmite, and it might cause frequency splitting that is at most an order of magnitude weaker than that observed.

Given that the modeling successfully predicts the main features of the stalagmite oscillations, it is tempting to move further with the modeling, on one hand by making the model even more realistic, e.g., by building a model based on a 3D laser scan of the stalagmite surface, and on the other hand, to move to time-dependent seismic forcing. The latter is particularly useful, since so far mostly static force has been applied. COMSOL and other Universal Finite Element Method (FEM)-based softwares, SAP2000 (Paskaleva et al. 2006; Valentini et al. 2016) or ANSYS, etc., can be used to perform dynamic structural analysis of the investigated stalagmites. Seismic action can be modelled either by using response-spectra curves of national building codes or of real earthquakes (Paskaleva et al. 2006; Valentini et al. 2016) or by using real or synthetic acceleration time histories (Bommer and Acevedo 2004). Realistic numerical modelling can successfully contribute to preliminary estimates of the breakage of stalagmites, including relevant stress level and the time when the rupture process starts (likely earlier than in static case). This is analogous to recent attempts to use realistic ground motion histories, e.g., measured strong ground motions, for modeling of building responses in structural engineering (e.g., Norman 1976; Norman and Wierzbicki 1987; Vamvatsikos and Cornell 2002).

\section{Conclusions}

Observed harmonic oscillations of a stalagmite from Domica cave, Slovakia, have been compared with FEM-based numerical calculations, to 
understand the characteristics of the resulting spectra, namely the eigenfrequencies, and especially their splitting, and what they are due to. For modeling the behaviour of the stalagmite under excitation, four approximate geometries of the stalagmite shape have been constructed. The main dimensions (height and average diameter) of the four approximate geometries of the stalagmite shape were more or less similar to the real ones, determined by the in situ measurements. The calculations were based on the formulation of the eigenoscillation problem, and a COMSOL Multiphysics software package was used for performing the numerical calculations. Based on the results of the numerical modeling the dominant frequencies could be explained, including the clear splitting behavior, which is caused by the asymmetries of the stalagmite.

\section{Acknowledgements}

Open access funding provided by University of Vienna. The authors wish to thank Zoltán Jerg and Ferenc Kovács (expert cavers) for professional support in the cave, and Lajos Gaál (Slovak Cave Administration) for helping us to find suitable stalagmites for our investigation purposes. We are also grateful to Marketa Lednicka (Institute of Geonics, Ostrava, Czech Republic) for determining the dynamic Young's modulus of broken stalagmite samples from Domica cave, Ördöglik Hall. We also acknowledge the suggestions of Orsolya KegyesBrassai and Balázs Pere (Széchényi István University, Győr, Hungary) about the failure process of beams and the appropriate usage of COMSOL software, and for the expert earthquake engineering suggestions of Mihaela Kouteva-Guentcheva (University of Architecture Civil Engineering and Geodesy, Sofia, Bulgaria). Dusan Bilcik (Earth Science Institute of the Slovak Academy of Sciences) operated the COMSOL software and the authors wish to thank for it. Anton Arpáš, Branislav Balžan and Matej Ruttkay (Institute of Archaeology, Slovak Academy of Sciences) prepared a 3D digital model of a stalagmite in another cave (Detreköi-zsomboly) by laser scanners. To use this 3D digital model of the Detrekői stalagmite is planned for Finite Element numerical modeling in the future, therefore we are grateful to them for preparing it. The in situ laser scanning of the stalagmite was supported by the ITMS 26220120059 project (Centre for the Research into the Oldest History of the Middle Danube River Basin). The in situ measurements in the Domica cave, Ördöglik Hall were financed by the Department of Meteorology and Geophysics, University of Vienna, and by the Research Centre for Astronomy and Earth Sciences, Hungarian Academy of Sciences. This paper was supported by the János Bolyai Research Scholarship of the Hungarian Academy of Sciences. The authors acknowledge discussions within TIDES COST Action ES1401. The two anonymous reviewers are thanked for their critical components, which have greatly improved the quality of this paper.

Open Access This article is distributed under the terms of the Creative Commons Attribution 4.0 International License (http:// creativecommons.org/licenses/by/4.0/), which permits unrestricted use, distribution, and reproduction in any medium, provided you give appropriate credit to the original author(s) and the source, provide a link to the Creative Commons license, and indicate if changes were made.

\section{Appendix 1: Finite Element Method for Linear Elasticity}

The Finite Element Method (FEM), introduced by engineers in the late 1950s and 1960s, is a common numerical technique in mechanical engineering for solving problems that can be described by partial differential equations (PDE) and appropriate boundary/initial conditions. It gives great flexibility to model complex geometries and can easily handle any type of general boundary conditions and variable material properties. FEM has a solid theoretical foundation which gives added reliability and makes it possible to mathematically analyze and estimate the error in the approximate solution. We illustrate this method based on the static problem under the conditions of equilibrium, in which all forces on the elastic body sum to zero and the displacements are not a function of time, together with the Neumann (stress) boundary condition: 


$$
\begin{aligned}
& \nabla \cdot \sigma=F \\
& n \cdot \sigma=g_{N}
\end{aligned}
$$

As a first step we construct the weak formulation by multiplying by a test function $v$ and integrating over the domain $\Omega$ :

$$
\int_{\Omega} v \cdot(-\nabla \cdot \sigma)=\int_{\Omega} v \cdot F .
$$

Using the Green's formula and substituting the stress, we obtain:

$$
\begin{aligned}
\int_{\Omega} & (\nabla v) \cdot\left[\mu\left(\nabla u+\nabla u^{T}\right)+\lambda(\nabla \cdot u) I\right] \\
= & \int_{\Omega} v \cdot F+\int_{\partial \Omega} v \cdot \sigma n .
\end{aligned}
$$

Rearranging and making use of the boundary condition leads us to the weak form of the linear elasticity problem: Find $\mathrm{u} \in H^{1}(\Omega)$ such that,

$$
\begin{aligned}
& \frac{\mu}{2} \int_{\Omega}\left(\nabla u+\nabla u^{T}\right) \cdot\left(\nabla v+\nabla v^{T}\right) \\
& \quad+\lambda \cdot \int_{\Omega}(\nabla \cdot u)(\nabla \cdot v) \\
& \quad=\int_{\Omega} v \cdot F+\int_{\partial \Omega} v \cdot g_{N} \\
& \forall v \in H^{1}(\Omega) .
\end{aligned}
$$

The two integrals on the left hand side characterize symmetric bilinear forms which we denote by $a(u, v)$ and $b(u, v)$, while on the right hand side the integrals define linear functionals which we denote by $f(v)$ and $g(v)$.

The next step is to assume that the solution can be written as a superposition of basis functions $\varphi_{i}$, $\mathrm{i}=1, \ldots, N$, i.e., $u=\sum_{i} u_{i} \varphi_{i}, v=\sum_{i} v_{i} \varphi_{i}$. Using the notation of bilinear forms and functionals and substituting the solution ansatz into the weak form allows us to extract the sums out of the integrals such that,

$$
\begin{aligned}
& \frac{\mu}{2} \sum_{i, j} u_{i} v_{j} a\left(\varphi_{i}, \varphi_{j}\right)+\lambda \sum_{i, j} u_{i} v_{j} b\left(\varphi_{i}, \varphi_{j}\right) \\
& \quad=\sum_{j} v_{j} f\left(\varphi_{j}\right)+\sum_{j} v_{i} g\left(\varphi_{j}\right)
\end{aligned}
$$

Using the vector-matrix-notation and canceling out the test vector $v$ leads us to the finite element system:

$$
\frac{\mu}{2} A u+\lambda B u=f+g
$$

More details on the existence and stability of such a solution can be found in Altenbach et al. (2013); Falk (2008).

\section{Appendix 2: Detailed Composition of the Different Stalagmite Models (From Bottom to Top)}

Here we give geometric parameters for the asymmetric, symmetric, cone and cylinder model. $h$ represents the height of small part of the stalagmite, and $H$ its total height; $r$ represents the radius, and $d_{x}$ is the shift of the axis of the cylinder. 


\begin{tabular}{|c|c|c|c|c|c|}
\hline \multicolumn{2}{|c|}{$\begin{array}{l}\text { Model A } \\
\text { Asymmetric model }\end{array}$} & \multicolumn{2}{|l|}{$\begin{array}{l}\text { Model B } \\
\text { Symmetric model }\end{array}$} & \multirow{3}{*}{$\begin{array}{l}\text { Model C } \\
\text { Cone } \\
\begin{array}{l}r_{1}=0.037 \mathrm{~m}, \\
r_{2}=0.025 \mathrm{~m}, H=4.61 \mathrm{~m}\end{array}\end{array}$} & \multirow{2}{*}{$\begin{array}{l}\text { Model D } \\
\text { Cylinder } \\
r=0.03 \mathrm{~m}, H=4.61 \mathrm{~m}\end{array}$} \\
\hline Cone 1: & & $\begin{array}{l}r_{1}=0.055 \mathrm{~m} \\
r_{2}=0.035 \mathrm{~m} \\
h=0.15 \mathrm{~m}\end{array}$ & & & \\
\hline Cone 2: & & $\begin{array}{l}r_{1}=0.035 \mathrm{~m} \\
r_{2}=0.03 \mathrm{~m} \\
h=1.15 \mathrm{~m}\end{array}$ & & & \\
\hline $\begin{array}{l}\text { Eccentric } \\
\quad \text { cylinder 1: }\end{array}$ & $\begin{array}{l}r=0.03 \mathrm{~m}, \\
h=0.02 \mathrm{~m}, \\
d_{x}=-0.03 \mathrm{~m}\end{array}$ & Cylinder 1: & $\begin{array}{l}r=0.03 \mathrm{~m} \\
h=0.02 \mathrm{~m}\end{array}$ & & \\
\hline Cone 3: & & $\begin{array}{l}r_{1}=0.03 \mathrm{~m} \\
r_{2}=0.025 \mathrm{~m} \\
h=1.0 \mathrm{~m}\end{array}$ & & & \\
\hline $\begin{array}{l}\text { Eccentric } \\
\quad \text { cylinder 2: }\end{array}$ & $\begin{array}{l}r=0.025 \mathrm{~m}, \\
h=0.02 \mathrm{~m}, \\
d_{x}=+0.03 \mathrm{~m}\end{array}$ & Cylinder 2: & $\begin{array}{l}r=0.025 \mathrm{~m} \\
h=0.02 \mathrm{~m}\end{array}$ & & \\
\hline Cylinder 3: & & $\begin{array}{l}r=0.025 \mathrm{~m} \\
h=1.25 \mathrm{~m}\end{array}$ & & & \\
\hline $\begin{array}{l}\text { Eccentric } \\
\quad \text { cylinder } 3:\end{array}$ & $\begin{array}{l}r=0.025 \mathrm{~m}, \\
h=0.02 \mathrm{~m}, \\
d_{x}=-0.03 \mathrm{~m}\end{array}$ & Cylinder 4: & $\begin{array}{l}r=0.025 \mathrm{~m} \\
h=0.02 \mathrm{~m}\end{array}$ & & \\
\hline Cone 4: & & $\begin{array}{l}r_{1}=0.025 \mathrm{~m} \\
r_{2}=0.02 \mathrm{~m} \\
h=1.0 \mathrm{~m}\end{array}$ & & & \\
\hline Total & & $H=4.61 \mathrm{~m}$ & & & \\
\hline
\end{tabular}

\section{REFERENCES}

Aki, K., \& Richards, P. G. (1981). Quantitative seismology: theory and methods, volumes I and II. San Francisco: W. H. Freeman and Co.

Allaei, D., Soedel, W., \& Yang, T. Y. (1986). Natural frequencies and modes of rings that deviate from perfect axisymmetry. Journal of Sound and Vibration, 111, 9-27.

Altenbach, H., Eremeyev, V. A., \& Lebedev, L. P. (2013). Mathematical study of boundary-value problems of linear elasticity with surface stresses, Vol. 30. In H. Altenbach \& N. F. Morozov (Eds.), Surface effects in solid mechanics. Advanced structured materials (pp. 1-19). Berlin: Springer.

Bao, H., Yagoda-Biran, G., \& Hatzor, Y. H. (2014). Site response analysis with two-dimensional numerical discontinuous deformation analysis. Earthquake Engineering and Structural Dynamics, 43, 225-246.

Bednárik, M. (2009). Seismometric portrayal of calcite tubular stalactites. Ph.D. thesis, Geophysical Institute, Slovak Academy of Sciences, p. 146.

Boch, R. (2008). Stalagmites from Katerloch cave, Austria: Growth dynamics and high-resolution records of climate change. PhD. thesis, Institute of Geology and Palaeontology, University of Innsbruck, p. 223.

Bommer, J. J., \& Acevedo, A. B. (2004). The use of real earthquake accelerograms as input to dynamic analysis. Journal of Earthquake Engineering, 8, 43-91.

Calais, E., Camelbeeck, T., Stein, S., Liu, M., \& Craig, T. J. (2016). A new paradigm for large earthquakes in stable continental plate interiors. Geophysical Research Letters, 43, 10621-10637. https://doi.org/10.1002/2016g1070815.

Day, D. M., \& Romero, L. A. (2004). An analytically solvable eigenvalue problem for the linear elasticity equations (p. 13). New Mexico: Sandia National Laboratories.

Falk, R. (2008). Finite element methods for linear elasticity. In D. Boffi \& L. Gastaldi (Eds.), Mixed finite elements, compatibility conditions, and applications, Lecture notes in mathematics, 1939. Berlin: Springer. pp. 159-194.

Gribovszki, K., Kovács, K., Mónus, P., Bokelmann, G., Konecny, P., Lednická, M., et al. (2017). Estimating the upper limit of prehistoric peak ground acceleration using an in situ, intact and vulnerable stalagmite from Plavecká priepast cave (Detrekőizsomboly), Little Carpathians, Slovakia-first results. Journal of Seismology, 21(5), 1111-1130. https://doi.org/10.1007/s10950017-9655-3.

Gribovszki, K., Kovács, K., Mónus, P., Shen, C.-C., Török, Á., \& Brimich, L. (2013a). Estimation of an upper limit on prehistoric peak ground acceleration using the parameters of intact stalagmites and the mechanical properties of broken stalagmites in Domica cave, Slovakia. Slovensky kras. Acta Carsologica Slovaca, 51(1), 5-14.

Gribovszki, K., Bokelmann, G., Szeidovitz, G., Varga, P., Paskaleva, I., Brimich, L., \& Kovács., K. (2013b). Comprehensive investigation of intact, vulnerable stalagmites to estimate an upper limit on prehistoric ground acceleration. In Proceedings of the vienna congress on recent advanced in earthquake engineering and structural dynamics \& 13. D-A-CH Tagung, Vienna, Paper No. 445, p. 10. 
Gribovszki, K., Paskaleva, I., Kostov, K., Varga, P., \& Nikolov, G. (2008). Estimating an upper limit on prehistoric peak ground acceleration using the parameters of intact speleothems in caves in southwestern Bulgaria. In A. Zaicenco, I. Craifaleanu, I. Paskaleva (Eds.) Harmonization of seismic hazard in Vrancea Zone with special emphasis on seismic risk reduction. NATO Science for peace and security, series C: environmental security (pp. 287-308). Dordrecht: Springer. (ISBN: 978-1-4020-9241-1).

Hegymegi, E., Gyöngy, M., Bodolai, T., Dívós, F., Barta, E., Gribovszki, K., Bokelmann, G., Hegymegi, Cs., Lednicka, M., \& Kovács, K. (2016). Non-destructive in situ mapping of macroholes, cracks and inhomogeneities of stalagmites in cave environments. Geophysical Research Abstracts, 18, Paper EGU2016-9425-2.

Konecny, P., Lednická, M., Soucek, K., Stas, L., Kubina, L., \& Gribovszki, K. (2015). Determination of dynamic Young's modulus of vulnerable speleothems. Acta Montanistica Slovaca, 20(2), 156-163. (ISSN 13351788).

Kong, S., Zhou, S., Nie, Z., \& Wang, K. (2008). The size-dependent natural frequency of Bernoulli-Euler micro-beams. International Journal of Engineering Science, 46, 427-437.

Labuschagne, A., van Rensburg, N., \& van der Merwe, A. (2009). Comparison of linear beam theories. Mathematical and Computer Modelling, 49, 20-30.

Lacave, C., Koller, M., \& Egozcue, J. (2004). What can be concluded about seismic history from broken and unbroken speleothems? Journal of Earthquake Engineering, 8, 431-455.

Lacave, C., Levret, A., \& Koller, M. (2000). Measurements of natural frequencies and damping of speleothems. In Proceedings of the 12th World Conference on Earthquake Engineering, Auckland, New-Zealand, Paper No. 2118, p. 7.

Lysmer, J., \& Kuhlemeyer, R. L. (1969). Finite dynamic model for infinite media. Journal of the Engineering Mechanics Division, ASCE, 95(EM4), 859-877.

Norman, J. (1976). Plastic failure of ductile beams loaded dynamically. Journal of Engineering for Industry, 98(1), 131-136.

Norman, J., \& Wierzbicki, T. (1987). Dynamic plastic failure of a free-free beam. International Journal of Impact Engineering, 6(3), 225-240.

Nováková, L., Sosna, K., Broz, M., Najser, J., \& Novak, P. (2011). Geomechanical parameters of the podlesi granites and their relationship to seismic velocities. Acta Geodynamics et Geomaterialia, 8(163), 353-369.

Paskaleva, I., Szeidovitz, G., Kostov, K., Koleva, G., Nikolov, G., Gribovszki, K., \& Czifra, T. (2006). Calculating the peak ground horizontal acceleration generated by paleoearthquakes from failure tensile stress of speleothems. In G. F. Panza (Ed.), Proceedings of the international conference on civil engineering design and construction, Varna, Bulgaria, pp. 281-286.

Pilkey, W. (2002). Analysis and design of elastic beams: computational methods (p. 480). New York: Wiley.

Scholz, H. (1990). The mechanics of the earthquakes and faulting (p. 467). Cambridge: Cambridge University Press.

Szeidovitz, G., Paskaleva, I., Gribovszki, K., Kostov, K., Surányi, G., Varga, Z., et al. (2008a). Estimation of an upper limit on prehistoric peak ground acceleration using the parameters of intact speleothems in caves situated at the western part of Balkan mountain range. Acta Geodaetica et Geophysica Hungarica, 43, 249-266.

Szeidovitz, G., Surányi, G., Gribovszki, K., Bus, Z., Leél-Ơssy, S., \& Varga, Z. (2008b). Estimation of an upper limit on prehistoric peak ground acceleration using the parameters of intact speleothems in Hungarian caves. Journal of Seismology, 12, 21-33.

Tóth, L., Mónus, P., Zsíros, T., Bondár, I., Bus, Z., Kosztyu, Z., Kiszely, M., Wéber, Z., \& Czifra, T. (1996-2014). Hungarian earthquake bulletin, 1995-2013. MTA GGKI és Georisk Kft, Budapest.

Valentini, A., Pace, B., Vasta, M., Ferranti, L., Colella, A., \& Vassallo, M. (2016). Could the collapse of a massive speleothem be the record of a large paleoearthquake? Geophysical Research Abstracts 18: Paper EGU20168187.

Vallabhaneni, A. K., Rhoads, J. F., Murthy, J. Y., \& Ruan, X. (2013). Defect-induced mechanical mode splitting in carbon nanotube resonators. Journal of Vibration and Acoustics, Transactions of the ASME, 135(2), 024504. https://doi.org/10. 1115/1.4023057.

Vamvatsikos, D., \& Cornell, C. A. (2002). Incremental dynamic analysis. Earthquake Engineering and Structural Dynamics, 31, 491-514. https://doi.org/10.1002/eqe.141.

Zsíros, T. (2000). The seismicity and seismic hazard of Carpathian basin: Hungarian earthquake catalog. (456-1995, in Hungarian), MTA GGKI Szeizmológiai Obszervatórium, p. 482. 